\title{
Unemployment with Observable Aggregate Shocks
}

\section{Citation}

Grossman, Sanford J., Oliver D. Hart, Eric S. Maskin. 1983. Unemployment with observable aggregate shocks. Journal of Political Economy 91(6): 907-928.

\section{Published Version}

doi:10.1086/261193

\section{Permanent link}

http://nrs.harvard.edu/urn-3:HUL.InstRepos:3448840

\section{Terms of Use}

This article was downloaded from Harvard University's DASH repository, and is made available under the terms and conditions applicable to Other Posted Material, as set forth at http:// nrs.harvard.edu/urn-3:HUL.InstRepos:dash.current.terms-of-use\#LAA

\section{Share Your Story}

The Harvard community has made this article openly available.

Please share how this access benefits you. Submit a story.

\section{Accessibility}




\title{
Unemployment with Observable Aggregate Shocks
}

\section{Sanford J. Grossman}

University of Chicago

\section{Oliver D. Hart}

London School of Economics

\section{Eric S. Maskin}

Massachusetts Institute of Technology

\begin{abstract}
A general equilibrium model of optimal employment contracts is developed where firms have better information about labor's marginal product than workers. It is optimal for the wage to be tied to the level of employment, to prevent the firm from falsely stating that the marginal product is low and cutting the wage. It is shown that an observed aggregate shock that leads to an interindustry shift in labor demand and that would have no effect on total employment under symmetric information leads to a reduction in employment when firms and workers have asymmetric information.
\end{abstract}

\section{Introduction}

Recent theories of the business cycle have emphasized the misallocations associated with unobserved aggregate shocks. ${ }^{1}$ Agents are assumed to have insufficient information to distinguish changes in their relative position from those in their absolute position. Here we develop an equilibrium model in which an aggregate shock (which, e.g.,

${ }^{1}$ See Barro (1981) for a survey of the literature on unobserved money supply shocks, and Grossman and Weiss (1982) for a model with unobserved real productivity shocks. 
affects the price level or aggregate unemployment) is observed by everyone. However, the shock increases workers' uncertainty about their marginal value products. We show that this increase in uncertainty causes employment to fall below the complete information level.

Grossman and Hart (1981) and Azariadis (1983) analyzed the optimal labor contract between a firm and its workers in a partial equilibrium model where the firm has better information than workers about the real profitability of employment. If the firm is risk averse, optimal risk sharing implies that it should cut its real wage bill when it suffers from low profitability. When the firm's profitability, $\tilde{s}$, is unobservable to workers, however, the wage bill cannot depend directly on $\tilde{s}$. Instead, if the wage bill is to be reduced, the firm will have to reduce employment as "proof" that labor's marginal product has fallen. In particular, the firm and workers will agree ex ante to a labor contract $w(l ; \tilde{n})$ that ties the wage bill $w$ to employment $l$, and the realization of a random variable $\tilde{n}$ denoting public information.

Suppose that when $\tilde{n}=n_{1}$, workers have complete information about their marginal value product, while $\tilde{n}=n_{2}$ denotes an aggregate shock that creates uncertainty about the marginal value product of labor. When $\tilde{n}=n_{1}$, the optimal labor contract will involve productive efficiency (since there is complete information), and hence the marginal wage bill $w_{l}\left(l, n_{1}\right)$ and labor's marginal disutility of effort, say $R$, will be equated. On the other hand, if $\tilde{n}=n_{2}$, it can be shown that risk sharing dictates that $w_{l}\left(l, n_{2}\right)$ exceed $R$. Hence there will be underemployment in low marginal product firms (but there will not be overemployment in high marginal product firms). This implies that total employment will be lower when $\tilde{n}=n_{2}$ than if information were complete or labor were allocated through Walrasian spot markets. Consequently, shocks that move the economy from $n_{1}$ to $n_{2}$ but do not affect total employment with complete information or with labor allocation through spot markets lower total employment when there is asymmetric information.

Section II reviews optimal asymmetric information contracts for a single firm. Section III presents an introductory general equilibrium model in which an observed economy-wide shock affects the physical productivity of labor. Workers know only the cross-sectional distribution of productivities across firms that the shock induces. For example, workers may know that an oil price shock lowers labor productivity by 75 percent in half the firms and raises it by 75 percent in the other half. However, a given worker does not know which half his firm is in. This captures the idea that workers know how the total demand for labor varies with the observed shock but not how their own firm's demand for labor is affected by the shock. We show that 
the relatively lucky firms do not increase employment more than they would if their workers had perfect information, while the unlucky firms decrease employment more than they would if their workers had perfect information.

Section IV extends the analysis to demand shocks. We consider an economy in which there are three final consumption goods, of which two, $X$ and $Y$, are produced from intermediate goods, $K_{1}$ and $K_{2}$, while the third is not produced using current resources (e.g., it represents real balances or the capital stock). The economy is subjected to two types of shocks, only one of which is observable to workers. First, the distribution of endowed wealth changes, which changes the demand for the final goods $X$ and $Y$. This results in an observable change in prices of the final goods. Second, there are shocks $\theta$ to the technology of transforming intermediate goods into final goods. These shocks are not observed by workers and change the intensity with which a particular final goods industry uses each intermediate good. Workers produce only intermediate goods but do not observe intermediate good prices.

When workers in a particular intermediate good industry, say industry 1, observe a shock to the relative prices of $X$ and $Y$, they do not know how that affects their marginal value product, because they do not know whether $X$ or $Y$ is intensively using the output $K_{1}$ they produce. Note, however, that when relative prices are not very dispersed, it does not matter as far as the workers' marginal value product is concerned whether $X$ or $Y$ is using $K_{1}$ intensively. The model, therefore, has the property that an observed increase in the dispersion of relative final goods prices causes an increase in the uncertainty workers have about their own marginal value products. This situation, where each worker knows more about general economic conditions than about conditions in his own industry (since each consumes goods produced in many industries), is in contrast to Lucas's (1972) assumption that workers know more about their own firms' price than they know about the economy-wide price level.

Using the results of Sections II and III, Section IV shows that an increase in the dispersion of relative prices that leaves the complete information Walrasian equilibrium unchanged causes a fall in employment under asymmetric information. This is proved under the assumption that, ex ante, workers and firms write an optimal labor contract that appropriately is conditioned on everything that will be observable to both parties. Therefore, the contractionary effect of aggregate shocks occurs despite the fact that contracts are conditioned on these shocks. This is in contrast to models such as Taylor (1980) or Blanchard (1979) where observable shocks affect output because wage contracts cannot be conditioned on them. 
Section V contains our interpretations, conclusions, and some references to evidence. In particular we suggest the importance of publicly observed but unanticipated changes in the price level (or rate of inflation) in a monetary economy. When a large percentage of individual wealth is held in the form of nominally denominated assets or liabilities, then changes in the price level will cause a redistribution of wealth between nominal borrowers and nominal lenders. This wealth redistribution can be the source of shocks to the relative demands for goods if borrowers and lenders have different tastes. Output can contract as a consequence of an increase in the relative price dispersion created by the wealth redistribution. A wealth redistribution that would have no effect on total employment when agents have symmetric information will cause employment to fall when they are asymmetrically informed.

\section{The Optimal Employment Contract}

We begin by analyzing the optimal contract between a single firm and its workers. For now, we do not distinguish physical productivity shocks from relative demand shocks. Thus we let $\tilde{s}$ represent a shock to the marginal value product of labor; that is, output $q$ is given by

$$
\tilde{q}=\tilde{s} f(l),
$$

where $l$ is total employment in the firm, and $f$ is a production function satisfying $f^{\prime}>0, f^{\prime \prime}<0, f^{\prime}(0)=\infty$, and $f^{\prime}(\infty)=0$. We regard $\tilde{q}$ as "real" output or revenue.

We adopt a 2-period model. At initial date 0 the firm and workers have the same information. Neither party knows $s$ ( $s$ denotes the realization of $\tilde{s}$ ), but both know the distribution of $s$. At date 1 the firm observes $s$, but the workers do not. This asymmetry reflects the reasonable presumption that management knows more about relevant demand and cost conditions than do workers. Because of the asymmetry, the wage bill cannot depend on $s$ directly (if the firm were asked to report $s$, it would claim the $s$ that minimized total wages). However, the workers and firm both observe $l$ and some public information $n$. Hence the total wage bill $w$ can depend on $n$ and $l$. We assume that $q$ is not observed by the workers.

Labor is supplied perfectly elastically at a real wage rate of $R$ per unit at date 1 ; that is, a worker's utility of real income $I$ and labor $l$ is $U(I-R l)$, where $U^{\prime}>0$ and $U^{\prime \prime} \leqslant 0$. Let $\bar{U}$ be the expected utility at time 0 that a worker at this firm could obtain elsewhere. We shall suppose, for simplicity, that the firm can hire only one worker (Grossman and Hart [1981, p. 304] show that real values are unaffected if the firm can have many identical workers). 
An optimal contract specifies a wage rule $w(l, \tilde{n})$ and an employment rule $l(\tilde{s}, \tilde{n})$ that maximize the firm's expected utility given that the worker's expected utility is at least $\bar{U}$. Note that since the worker cannot observe $s$ directly, the contract must induce the firm to choose $l$ $=l(s, n)$, given $w(l, n)$, when $\tilde{s}=s$ and $\tilde{n}=n$. The firm will do so if

$$
s f[l(s, n)]-w[l(s, n), n] \geqslant s f(\hat{l})-w(\hat{l}, n)
$$

for all $s, \hat{l}, n$; that is, if $l(s, n)$ maximizes ex post profit for the firm at date 1 when $\tilde{s}=s, \tilde{n}=n$, given the wage rule $w(l, \tilde{n}) .^{2}$ We assume that the owners of the firm are risk averse and have a utility of profit $V(q-w)$, where $V$ is strictly concave." Thus an optimal contract maximizes

$$
E V\{\tilde{s} f[l(\tilde{s}, \tilde{n})]-w[l(\tilde{s}, \tilde{n}), \tilde{n}]\}
$$

subject to (2) and

$$
E U\{w[l(\tilde{s}, \tilde{n}), \tilde{n}]-R l(\tilde{s}, \tilde{n})\} \geqslant \bar{U} .
$$

Expectations are taken with respect to the joint distribution of $\tilde{s}$ and $\tilde{n}$, which is assumed to be known to both the firm and worker at time 0 .

If the worker could observe $s$, then an optimal employment contract would set the marginal value product of labor equal to the value of the marginal disutility of effort $R$ and choose the wage bill to share risk optimally between the firm and the worker. We denote this complete information employment rule by $l^{*}(\tilde{s})$, where

$$
s f^{\prime}\left[l^{*}(s)\right]=R \text { for all } s .
$$

Grossman and Hart (1981) showed that when the worker has no information $\tilde{n}$ about the realization of $\tilde{s}$, the optimal employment function $l(s)$ is everywhere below $l^{*}(s)$ except at the highest $s$. This result extends to the case where workers can observe $n$ at time 1 . In the following proposition, $[\underline{s}(n), \bar{s}(n)]$ denotes the support of the conditional distribution of $s$ given $n$.

\footnotetext{
2 It is sometimes convenient to express a contract as a pair $\left[u^{\prime}(\tilde{s}, \tilde{n}), l(\bar{s}, \tilde{n})\right]$ with the property that for all $s, \hat{s}, n$

$$
\hat{s} f[l(\hat{s}, n)]-w(\hat{s}, n) \geqslant \hat{s} f[l(s, n)]-w(s, n) .
$$

This formulation is equivalent to $\left(2^{\prime}\right)$ in the text because from $\left(2^{*}\right) w\left(s_{1}, n\right)=w^{\prime}\left(s_{2}, n\right)$ whenever $l\left(s_{1}, n\right)=l\left(s_{2}, n\right)$; i.e., $w(s, n)$ depends on $s$ only through $l$. That we may use this alternative expression is an instance of the revelation principle (see Dasgupta, Hammond, and Maskin 1979; Myerson 1979; or Harris and Townsend 1981). Inequalities (2) and $(2 *)$ are often called incentive or self-selection constraints.

${ }^{3}$ The assumption that we can treat the firm as risk averse makes sense if either $(a)$ the owners cannot diversify away the riskiness of their shares in the firm or $(b)$ the firm is run by a risk-averse manager who supplies an unobserved input (e.g., "entrepreneurial effort") and whose salary depends on the firm's performance. For elaborations of the second justification, see Holmstrom and Weiss (1982) and Hart (1983).
} 
Proposition 1. If $l^{0}(s, n)$ and $w^{0}(l, n)$ form an optimal contract, that is, maximize (3) subject to (2) and (4), then $l^{(0}(s, n) \leq l^{*}(s)$ for all $s$ and $n$, with equality if $s=\bar{s}(n)$. Furthermore, if, for each $n$, either $(a)$ the conditional distribution of $\tilde{s}$ is continuous or $(b)$ it is discrete and the worker is risk neutral, then $l^{0}(s, n)<l^{*}(s)$ almost surely for those realizations $s$ less than $\bar{s}(n){ }^{4}$

The first part of proposition 1 is established in Hart (1983). Part $b$ is also proved there, while $a$ follows from an application of the results of Grossman and Hart (1981).

To illustrate this proposition, suppose that $\tilde{n}$ takes on two possible values, $n_{1}$ and $n_{2}$. Assume that when $n=n_{1}, \tilde{s}=s_{1}$ always, so there is no uncertainty; whereas when $n=n_{2}, \tilde{s}$ can assume two values $\underline{s}$ and $\bar{s}$. Clearly the conditionally optimal contract for $n=n_{1}$ entails efficient employment, $l *\left(s_{1}\right)$, since there is no uncertainty. On the other hand, when $n=n_{2}, l\left(\underline{s}, n_{2}\right)<l^{*}(\underline{s})$ (assuming risk neutrality for the worker) by proposition 1 .

To understand proposition 1 in this case, suppose instead that a labor contract induced the full information employment rule, $l^{*}(s)$. From the incentive constraint (2),

$$
\bar{s} f\left[l^{*}(\bar{s})\right]-w(\bar{s}) \geqslant \bar{s} f\left[l^{*}(\underline{s})\right]-w(\underline{s}) .
$$

The difference in the firm's profit across the two states is

$$
\pi_{2}-\pi_{1}=\bar{s} f\left[l^{*}(\bar{s})\right]-w(\bar{s})-\left\{\underline{s} f\left[l^{*}(s)\right]-w(\underline{s})\right\},
$$

which, by $\left(2^{\prime}\right)$, is positive, since $l^{*}(\bar{s})>l^{*}(\underline{s})$. Thus the firm bears risk. Now if $\left(2^{\prime}\right)$ held with strict inequality, we could raise $w(\bar{s})$ and lower $w(\underline{s})$ to keep the mean wage the same. This would not affect the worker if he were risk neutral but would help the firm by reducing its risk. Hence $\left(2^{\prime}\right)$ must hold with equality (it is immediate that, if [2'] holds with equality, the other incentive constraint for $s=\underline{s}$ holds). From $\left(2^{\prime}\right)$ and $\left(2^{\prime \prime}\right)$, it is clear that the only way to reduce $\pi_{2}-\pi_{1}$ while still maintaining $\left(2^{\prime}\right)$ with equality is to reduce $l(\underline{s})$ below $l^{*}(\underline{s})$ and raise $w(\bar{s})-w(\underline{s})$. Moreover, such a change is desirable, assuming the worker is risk neutral, since the consequent loss of output is a secondorder effect (starting from efficiency) but the gain in risk reduction for the firm is of the first order. Note also that since deviations in $l(\bar{s})$ from $l^{*}(\bar{s})$ do not affect $\pi_{2}-\pi_{1}$, it is optimal to set $l(\bar{s})=l^{*}(\bar{s})$.

For the remainder of the paper, when applying proposition 1 , we shall suppose that either case $a$ or case $b$ holds.

\footnotetext{
${ }^{4}$ Risk neutrality of the worker is a stronger assumption than is necessary. All that is required is that the worker be not too risk averse.
} 


\section{General Equilibrium with Physical Productivity Shocks}

We now embed the partial equilibrium model of Section II in a very simple general equilibrium model of contracts. In this model aggregate shocks affect the marginal physical productivity of labor.

As in Section II, each firm $i$ has a production function

$$
q_{i}=s_{i} f\left(l_{i}\right) \text {. }
$$

We imagine that there is a steady state for the economy in which firms earn no rents. In this steady state, all firms find labor equally profitable; that is, $s_{1}=s_{2}=\ldots=s^{*}$. Now imagine that the economy is hit by a shock that induces a nondegenerate distribution of $\tilde{s}$ across firms. We assume that the owner of each firm knows his own $s$ but that his worker knows only the cross-sectional distribution of $\tilde{s}$. Lacking any further knowledge, each worker assumes that his firm's $s$ is a random drawing from that distribution.

In the notation of the previous section, let $\tilde{n}$ be the signal observed by firms and workers about the economy-wide shock. Let $F(s \mid n)$ be the cross-sectional distribution of productivities associated with the realization $\tilde{n}=n$. Denote the news that no shock has occurred by $\tilde{n}=$ $n^{*}$; that is, this is the steady state where $s_{i}=s^{*}$ for all $i$. We assume that every $n \neq n^{*}$ leads to a nondegenerate distribution of $s$ in the sense that

$$
\operatorname{var}(\tilde{s} \mid n)>0 \text { for all } n \neq n^{*} .
$$

It is useful to consider the Walrasian (or complete information) employment level associated with a particular cross-sectional distribution of $\tilde{s}$. A firm with $s_{i}=s$ sets

$$
s f^{\prime}\left(l^{*}\right)=R \text {. }
$$

This defines the employment level $l^{*}(s)$. Thus for a given crosssectional distribution $F(s \mid n)$, economy-wide employment is

$$
L^{*}(n)=\int_{\underline{s}(n)}^{s(n)} l *(s) d F(s \mid n)
$$

where $\underline{s}(n)$ and $\bar{s}(n)$ are the bounds on the realization of $s$. Note that for the no-shock situation, total employment is

$$
L^{*} \equiv L^{*}\left(n^{*}\right)=l^{*}\left(s^{*}\right) N,
$$

where $N$ is the number of firms.

Suppose now that the worker in firm $i$ can observe $l_{i}$ and $n$ but not $s_{i}$. Appealing to proposition 1 of Section II, we see that when the cross- 
sectional distribution of $\tilde{s}$ is not degenerate, employment $l^{0}(s, n)$ satisfies

$$
l^{0}(s, n)<l^{*}(s) \text { for } s<\bar{s}(n)
$$

almost surely. Hence the economy's total employment under asymmetric information is

$L^{0}(n)=\int_{\underline{s}(n)}^{\bar{s}(n)} l^{0}(s, n) d F(s \mid n)<\int_{\underline{s}(n)}^{\bar{s}(n)} l^{*}(s) d F(s \mid n)=L^{*}(n) \quad$ for all $n \neq n^{*}$.

On the other hand,

$$
L^{0}\left(n^{*}\right)=L^{*}\left(n^{*}\right)=L^{*},
$$

since the asymmetry of information is irrelevant when there is no shock.

Using (12) and (13) we may compare the asymmetric and full information employment levels. In the steady state, total employment equals $L^{*}$ under both symmetric and asymmetric information. Assume now that a shock hits the economy inducing a nondegenerate cross-sectional distribution of $\tilde{s}$. In general, some firms gain from this shock while others lose. The lucky firms will raise employment, whereas the losers will diminish it.

If the move from $n^{*}$ to $n$ causes total Walrasian employment to fall below $L^{*},(12)$ and (13) imply that, under asymmetric information, the decline in total employment is greater, that is, it is multiplied. On the other hand, if total Walrasian employment rises when $n^{*}$ goes to $n$ the increase must be smaller under asymmetric information; there is a "divider" effect. Finally, any movement from $n^{*}$ to $n$ that keeps the total level of Walrasian employment constant will lead to a decrease in aggregate employment under asymmetric information.

We see, therefore, that the effect of the asymmetry of information is itself asymmetric between "up shocks" and "down shocks" (where these are defined relative to total Walrasian employment). In the case of down shocks, the fall in Walrasian employment is exacerbated, whereas in the case of up shocks the rise is diminished. The model thus contrasts with that of Lucas (1972), in which asymmetric information has a (symmetric) multiplier effect on both up and down shocks.

Note that there is some reason to believe that the non-Walrasian effects of our model will be short run. For if the shock is permanent, there should be a flow of resources from adversely affected firms or industries to beneficially affected ones. This reallocation will tend to equalize the profitability of labor, returning the economy to a steady state. 


\section{Relative Demand Shocks}

We next study uncertainty caused by relative demand shocks. Such uncertainty is more difficult to formalize than that from productivity shocks. The additional complication is rewarded, however, by a richer model. Moreover, relative demand shocks are arguably more important in practice as a source of uncertainty.

One possible cause of relative demand shocks is redistribution of wealth (induced, perhaps, by unanticipated changes in inflation). If workers do not know how a shift in demand affects their own firm, a redistribution of wealth may increase their uncertainty about their marginal value product. This uncertainty may cause a decline in aggregate employment relative to the Walrasian level.

There are a number of difficulties in formalizing this idea. First, the process we are trying to capture is intrinsically dynamic: a demand shift alters prices, which in turn influence employment, which then further affects demand, and so on. Ideally, we should use an intertemporal, monetary model. Instead, ours is nonmonetary and static.

Second, there is a special problem with modeling shocks to demand rather than to productivity, namely, that if firms operate in competitive product markets, the demand they face is completely summarized by the relative prices of their products. If workers buy these products, they cannot have imperfect information about their firm's demand. ${ }^{5}$

To get around this problem, we assume that some firms produce intermediate goods at prices that consumers do not observe. Thus a worker does not know how a change in the demand for a final consumption good affects the demand for the particular intermediate good produced by his firm. All he knows is that his firm's price is a random drawing from the current cross-sectional distribution of all intermediate good prices.

Consider a competitive economy with two produced consumption goods $X$ and $Y$ and two intermediate goods $K_{1}$ and $K_{2}$. There is also an unproduced third consumption good $Z$. There are firms that produce good $K_{1}$ (type 1 firms) and others that produce good $K_{2}$ (type 2 firms). Both types have the same concave, differentiable production function, $f(l)$, where $l$ is labor input, as in Section II. Goods $X$ and $Y$ are produced without labor according to the linear production

\footnotetext{
${ }^{5}$ If there are no futures markets, and labor at time $t$ is used to produce goods at time $t+1$, then it might appear that workers and firms could have different information about the value of employing labor at $t$. However, if the workers' wage at clate $t+1 \mathrm{can}$ depend on the date $t+1$ spot prices that the firm learns at $t$, then one can show that employment in an optimal contract is the same as if both the firm and workers observed the date $t+1$ spot price at date $t$.
} 
technologies

$$
\begin{aligned}
& X=(1-\theta) K_{1}+\theta K_{2} \\
& Y=\theta K_{1}+(1-\theta) K_{2},
\end{aligned}
$$

where $\theta$ is the realization of a random variable $\tilde{\theta}$. We assume that $\tilde{\theta}$ takes two values:

$$
\tilde{\theta}= \begin{cases}1 / 2+b & \text { with probability } 1 / 2 \\ 1 / 2-b & \text { with probability } 1 / 2,\end{cases}
$$

where $0<b<1 / 2$. When $\theta>1 / 2$, industry $\mathrm{Y}$ finds $K_{1}$ a more productive input than $K_{2}$, while industry $\mathrm{X}$ finds the opposite true. The roles are reversed when $\theta<1 / 2$. We will see that, when $\theta>1 / 2$, industry $\mathrm{Y}$ uses only $K_{1}$, and industry $\mathrm{X}$ uses only $K_{2}$. Thus, when $\theta>1 / 2$, an increase in the final demand for $X$ relative to $Y$ is beneficial for type 2 firms, whereas when $\theta<1 / 2$ it is adverse. That is, the benefits that intermediate good firms derive from changes in final demand depend on the realization of $\tilde{\theta}$.

We normalize the price of the third consumption good $Z$ to be 1 . For the rest of this section all prices are measured in terms of $Z$. Let $v_{i}$ be the price of intermediate good $K_{i}$. Let $P_{x}$ and $P_{y}$ be the prices of $X$ and $Y$, respectively.

There are two cases to consider:

Case 1: $\theta<1 / 2$. In this case,

$$
\frac{\theta}{1-\theta}<\frac{1-\theta}{\theta} \text {. }
$$

If $v_{2} / v_{1}>(1-\theta) / \theta$, neither consumption good industry will demand $K_{2}$. But, as will become clear, a positive quantity of $K_{2}$ is always supplied, a contradiction of equilibrium. Similarly, $\tau_{r_{2}} / \tau_{1}<\theta /(1-\theta)$ is also impossible. Hence

$$
\frac{\theta}{1-\theta} \leqslant \frac{v_{2}}{v_{1}} \leqslant \frac{1-\theta}{\theta},
$$

and industries $\mathrm{X}$ and $\mathrm{Y}$ specialize in $K_{1}$ and $K_{2}$, respectively. Competition implies that if $X$ and $Y$ are produced their prices must equal unit resource costs:

$v_{1}=P_{x}(1-\theta)=P_{x}\left(\frac{1}{2}+b\right), v_{2}=P_{y}(1-\theta)=P_{y}\left(\frac{1}{2}+b\right)$.

CASE 2: $\theta>1 / 2$. Symmetrically, we have

$$
\frac{1-\theta}{\theta} \leqslant \frac{v_{2}}{v_{1}} \leqslant \frac{\theta}{1-\theta}
$$


and

$$
v_{1}=P_{y} \theta=P_{y}\left(\frac{1}{2}+b\right), v_{2}=P_{x} \theta=P_{x}\left(\frac{1}{2}+b\right) .
$$

Notice that the cross-sectional distribution of final good prices is mirrored by the cross-sectional distribution of intermediate good prices. A worker who observes the prices $\left(P_{x}, P_{y}\right)$ and has only this information views his own firm's price $v$ as a random drawing from the distribution

$$
\tilde{v}= \begin{cases}P_{x}(.5+b) & \text { with probability } 1 / 2 \\ P_{y}(.5+b) & \text { with probability } 1 / 2 .\end{cases}
$$

Thus the worker can make good inferences about his own firm's price if the dispersion of $P_{x}$ and $P_{y}$ is small but correspondingly poor inferences for large dispersions. ${ }^{6}$

We next study optimal labor contracts between firms and workers in the intermediate good industries. To do so we first specify agents' preferences.

\section{Workers and Firms in the Intermediate Good Industries}

There are $m$ intermediate good firms and $m$ workers. All workers are identical and have ordinal preferences represented by the utility function $X^{\lambda_{1}} Y^{\lambda_{2}} Z^{\lambda_{3}}-R L$, where $R$ is the marginal disutility of effort, $\lambda_{i} \geqslant 0$ for all $i$, and $\lambda_{1}+\lambda_{2}+\lambda_{3}=1$. Workers' risk preferences are represented by the concave von Neumann-Morgenstern utility function $U$, so their utility over consumption is $U\left(X^{\lambda_{1}} Y^{\lambda_{2}} Z^{\lambda_{3}}\right.$ $-R L)$. Collectively, they have endowment $e_{u}$ of the nonproduced good Z. Firms' owners (we identify firms with their owners) have the same tastes for consumption goods as workers; they have the utility functions $X^{\lambda_{1}} Y^{\lambda_{2}} Z^{\lambda_{3}}$. They have the strictly concave von NeumannMorgenstern utility function $V$, and so their overall utility is $V\left(X^{\lambda_{1}} Y^{\lambda_{2}} Z^{\lambda_{33}}\right)$. Owners have an aggregate endowment $e_{f}$ of the unpro-

\footnotetext{
${ }^{6}$ We want to model the idea that workers know general labor market conditions better than conditions in their own firm. Thus workers observe the cross-sectional mean and variance of employment from newspaper reports on the economy-wide and regional unemployment rates. They do not know the state of demand for their own firm's product. Further, if there are many firms in a given industry, then the employment level of other identical firms will provide a useful signal to workers in a given firn. We assume that no such signal is azailable. To the extent that firms in the same industry are not completely identical but are subject to idiosyncratic shocks to demand, the employment level of other firms in the same industry may be a poor signal about a given firm? demand.
} 
duced good. Aggregate worker and firm demand for $X$ and $Y$ is

$$
X^{d}=\frac{\lambda_{1}}{P_{x}}\left(I_{w}+I_{F}\right), \quad Y^{d}=\frac{\lambda_{2}}{P_{y}}\left(I_{w}+I_{F}\right),
$$

where $I_{w}$ and $I_{F}$ are the aggregate incomes for workers and firm owners, respectively. Define $\delta \equiv \lambda_{1}^{\lambda_{1}} \lambda_{2}^{\lambda_{2}{ }^{2}} \lambda_{3}^{\lambda_{3}}$. Then the indirect utility functions of workers and firms are, respectively,

$$
U\left(\delta P_{x}^{-\lambda_{1}} P_{y}^{-\lambda_{2}} \frac{I_{w}}{m}-R l\right), \quad V\left(\delta P_{x}^{-\lambda_{1}} P_{y}^{-\lambda_{2}} \frac{I_{F}}{m}\right) .
$$

The aggregate income of workers and owners together automatically nets out wage payments, so it equals total income from sales of intermediate goods plus aggregate endowment of the nonproduced good $Z$ :

$$
I_{w}+I_{F}=v_{1} K_{1}+v_{2} K_{2}+e_{f}+e_{w}=P_{x} X+P_{y} Y+e_{f}+e_{w} .
$$

We model the economy as if there were two dates, 0 and 1 . At date 0 the workers and firms meet according to some competitive process to sign contracts. From the equal numbers assumption each firm employs one worker. Everyone knows the distributions, but not the realizations, of $\tilde{\theta}, \tilde{P}_{x}$, and $\tilde{P}_{y}$. Since the distribution of $\tilde{\theta}$ is symmetric about $1 / 2$, workers are indifferent between signing contracts with $K_{1}$ and $K_{2}$ firms. Let $\tilde{n}$ denote $\left(\tilde{P}_{x}, \tilde{P}_{y}\right)$. Then workers and firms write a contract that makes the wage bill paid at date 1 a function $w(l, \tilde{n})$. At date 1 the firm observes $n$ and its own price $v$ and chooses $l$, whereas the worker observes only $l$ and $n$.

\section{Other Consumers}

There are other consumers who neither work nor own intermediate goods firms. The only source of wealth these consumers have is their (random) aggregate endowment $\tilde{e}_{0}$ of the nonproduced good. They have Cobb-Douglas utility functions but with parameters different from those of firms and workers, namely, $\gamma_{1}, \gamma_{2}, \gamma_{3}$. Their demands are

$$
X_{0}^{d}=\frac{\gamma_{1}}{P_{x}} e_{0}, \quad Y_{0}^{d}=\frac{\gamma_{2}}{P_{y}} e_{0} .
$$

The only role of the other consumers is to generate changes in relative prices when the wealth distribution changes. We could alternatively have considered a wealth redistribution between firms and workers, but it is more difficult to characterize the optimal labor contract when workers and firms have different tastes for consumer goods. 


\section{Equilibrium}

Let $\tilde{e} \equiv\left(e_{f}, e_{w}, \tilde{e}_{0}\right)$. In equilibrium, consumption prices $n \equiv\left(P_{x}, P_{y}\right)$ are functions of $e$. In turn, intermediate goods prices, from (19) and (21), are functions of $n$ and $\theta$. Thus, given the distribution of $\tilde{n}$ and $\tilde{\theta}$, the optimal labor contract $\left[w_{i}(l, \tilde{n}), l_{i}\left(\tilde{v}_{i}, \tilde{n}\right)\right]$ for firms in industry $i$ maximizes

$$
E V\left\{\frac{v_{i} f\left[l_{i}\left(\tilde{v}_{i}, n\right)\right]-w_{i}\left[l_{i}\left(\tilde{v}_{i}, \tilde{n}\right), \tilde{n}\right]+\left(e_{f} / m\right)}{\delta^{-1} \tilde{P}_{x}^{\lambda_{1}} \tilde{P}_{y}^{\lambda_{2}}}\right\}
$$

subject to the constraints that $l_{i}\left(v_{i}, n\right)$ maximizes

$$
v_{i} f\left(l_{i}\right)-w_{i}\left(l_{i}, n\right),
$$

for all $n$ and $v$, and

$$
E U\left\{\frac{w_{i}\left[l_{i}\left(\tilde{v}_{i}, \tilde{n}\right), \tilde{n}\right]+\left(e_{u} / m\right)}{\delta^{-1} \tilde{P}_{x}^{\lambda_{1}} \tilde{P}_{y}^{\lambda_{2}}}-R l_{i}\left(\tilde{v}_{i}, \tilde{n}\right)\right\} \geqslant \bar{U} .
$$

The expectations in (27) and (29) are taken ex ante over the prospective market-clearing prices $P_{x}(e), P_{y}(e)$, and $v_{1}(e, \theta), v_{2}(e, \theta)$. Because firms in the two intermediate goods industries are ex ante identical, we will henceforth drop the subscript $i$ and refer to the optimal contract as a pair $w(l, n), l(v, n){ }^{7}$

In equilibrium $P_{x}$ and $P_{y}$ must clear spot markets at date 1 . In view of (23), (25), and (26), we have

$$
\frac{\lambda_{1}}{P_{x}}\left(P_{x} X+P_{y} Y+e_{f}+e_{w}\right)+\frac{\gamma_{1}}{P_{x}} e_{0}=X
$$

and

$$
\frac{\lambda_{2}}{P_{y}}\left(P_{x} X+P_{y} Y+e_{f}+e_{w}\right)+\frac{\gamma_{2}}{P_{y}} e_{0}=Y,
$$

where $X$ and $Y$ are outputs of the two produced goods. Manipulating (30a) and (30b) yields

$$
X=\frac{E_{x}}{P_{x}}, \quad Y=\frac{E_{y}}{P_{y}},
$$

where $E_{x}$ and $E_{y}$ are given by ${ }^{8}$

$$
E_{x} \equiv\left(e_{f}+e_{w}\right)\left[\frac{\lambda_{1}}{\lambda_{3}}\left(\lambda_{1}+\lambda_{2}\right)+\lambda_{1}\right]+e_{0}\left[\frac{\lambda_{1}}{\lambda_{3}}\left(\gamma_{1}+\gamma_{2}\right)+\gamma_{1}\right]
$$

\footnotetext{
${ }^{7}$ It is not difficult to show that under our assumptions the optimal contract is unique.

${ }^{8}$ Note that when $\lambda_{i}=\gamma_{i}$ for all $i$, changes in the distribution of wealth have no effect on $E_{x}$ or $E_{y}$ and so none on prices.
} 


$$
E_{y} \equiv\left(e_{f}+e_{w}\right)\left[\frac{\lambda_{2}}{\lambda_{3}}\left(\lambda_{1}+\lambda_{2}\right)+\lambda_{2}\right]+e_{0}\left[\frac{\lambda_{2}}{\lambda_{3}}\left(\gamma_{1}+\gamma_{2}\right)+\gamma_{2}\right] .
$$

Let $l_{x}$ and $l_{y}$ be employment in the intermediate good industries supplying industries X and Y, respectively. Then, from (22),

$$
l_{x}=l\left[\left(\frac{1}{2}+b\right) P_{x}, n\right], \quad l_{y}=l\left[\left(\frac{1}{2}+b\right) P_{y}, n\right] .
$$

Outputs $X$ and $Y$ are given by

$$
X=(1-\theta) K_{1}=(1-\theta) f\left(l_{x}\right), \quad Y=(1-\theta) K_{2}=(1-\theta) f\left(l_{y}\right),
$$

if $\theta<1 / 2$, and

$$
X=\theta K_{2}=\theta f\left(l_{x}\right), \quad Y=\theta K_{1}=\theta f\left(l_{y}\right),
$$

if $\theta>1 / 2$. Since $\theta=1 / 2-b$ or $1 / 2+b$, this simplifies to

$$
X=\left(\frac{1}{2}+b\right) f\left(l_{x}\right), \quad Y=\left(\frac{1}{2}+b\right) f\left(l_{y}\right) .
$$

Combining (31) and (34) gives us

$$
(.5+b) f\left(l_{x}\right)=\frac{E_{x}}{P_{x}} \text { and }(.5+b) f\left(l_{y}\right)=\frac{E_{y}}{P_{y}} .
$$

Conditions (22), (27)-(29), and (33)-(35) characterize a contract equilibrium under asymmetric information. To summarize the features of this equilibrium, a price function $P(\tilde{e})=\left[P_{x}(\tilde{e}), P_{y}(\tilde{e})\right]$ maps each realization of the random endowment vector $\tilde{e}=\left(e_{f}, e_{t^{\prime}}, \tilde{e}_{0}\right)$ into a pair of prices. This function determines intermediate goods prices $v_{1}(e, \theta), v_{2}(e, \theta)$ according to (22). Given these price functions, optimal labor contracts maximize (27) subject to (28) and (29). These contracts determine output through (33) and (34). Finally, for the system to be in equilibrium, these supplies must clear markets, that is, satisfy (35). ${ }^{9}$

It is useful by contrast to examine the Walrasian equilibrium as a function of $E \equiv\left(E_{x}, E_{y}\right) .{ }^{10}$ Walrasian wages in each industry are equal to marginal value products of labor. This implies that the Walrasian equilibrium prices and employment levels, $\bar{v}_{x}, \bar{v}_{y}, \bar{P}_{x}, \bar{P}_{y}, \bar{l}_{x}, \bar{l}_{y}$, satisfy

$$
\frac{\delta \bar{v}_{x} f^{\prime}\left(\bar{l}_{x}\right)}{\bar{P}_{x}^{\lambda_{1}} \bar{P}_{y}^{\lambda_{2}}}=\frac{\delta \bar{P}_{x}(.5+b) f^{\prime}\left(\bar{l}_{x}\right)}{\bar{P}_{x}^{\lambda_{1}} \bar{P}_{y}^{\lambda_{2}}}=R
$$

${ }^{9}$ We must also add the condition that $U^{* *} \leqslant \bar{U} \leqslant U^{*}$, where $U^{*}$ is the level of utility at which a firm is indifferent between signing a contract with a worker and not operating at all, and $U^{* *}$ is the level of utility at which a worker is indifferent between signing a contract with a firm and not working; i.e., $U^{* *}=E U\left[\delta \tilde{P}_{s}^{-\lambda_{1}} \tilde{P}_{y}^{-\lambda^{2}}\left(\rho_{z} / m\right)\right]$. Equilibrium depends, in general, on the particular value $\bar{U}$ (not, however, if $U$ and $V$ exhibit constant absolute risk aversion; see Grossman and Hart 1983). It can be shown that a contract equilibrium exists.

${ }^{10}$ Alternatively, we could examine the contract equilibrium with complete information. Such an equilibrium gives rise to the Walrasian employment levels. 


$$
\begin{gathered}
\frac{\delta \bar{v}_{y} f^{\prime}\left(l_{y}\right)}{\bar{P}_{x}^{\lambda_{1}} \bar{P}_{y}^{\lambda_{2}}}=\frac{\delta \bar{P}_{y}(.5+b) f^{\prime}\left(\bar{l}_{y}\right)}{\bar{P}_{x}^{\lambda_{1}} \bar{P}_{y}^{\lambda_{2}}}=R ; \\
X=(.5+b) f\left(\bar{l}_{x}\right)=\frac{E_{x}}{\bar{P}_{x}} ; \\
Y=(.5+b) f\left(\bar{l}_{y}\right)=\frac{E_{y}}{\bar{P}_{y}}
\end{gathered}
$$

where (38) and (39) are the market-clearing conditions for the two produced goods industries (see the derivation of [31]).

We now apply proposition 1 to the asymmetric information contract equilibrium. For a given realization of $\tilde{n}=\left(\tilde{P}_{x}, \tilde{P}_{y}\right)$, there will be a "lucky" intermediate goods industry (one whose output price is high) and an "unlucky" industry (i.e., if $P_{x}>P_{y}$, industry 2 is lucky if $\theta$ $>1 / 2$ and unlucky if $\theta<1 / 2$ and conversely for industry 1$)$. One difference between $(27)-(29)$ and $(2)-(4)$ is that workers and firms are interested in real income $\delta I P_{x}^{-\lambda_{1}} P_{y}^{-\lambda_{2}}$ rather than in $I$. Given that $P_{x}, P_{y}$ are publicly observable, however, proposition 1 generalizes to this case (for details, see Hart [1983]). Hence, we may conclude that a firm in the lucky industry will equate the marginal value product of labor and the marginal disutility of effort, whereas a firm in the unlucky industry will set the marginal product of labor above the marginal disutility of effort. Specifically, when, say, $P_{x} \geqslant P_{y}$, employment satisfies

$$
\begin{gathered}
\frac{\delta P_{x}}{P_{x}^{\lambda_{1}} P_{y}^{\lambda_{2}}}(.5+b) f^{\prime}\left(l_{x}\right)=R \\
\frac{\delta P_{y}}{P_{x}^{\lambda_{1}} P_{y}^{\lambda_{2}}}(.5+b) f^{\prime}\left(l_{y}\right)=R(1+\alpha),
\end{gathered}
$$

where $\alpha \geqslant 0$, and $\alpha=0$ if and only if $P_{x}=P_{y}$. Thus, the crucial difference between the asymmetric information and Walrasian equilibrium conditions is the $\alpha$ in (41).

We now show that if the distribution of wealth induces prices that create uncertainty for workers about their marginal value products, then total employment is lower than with complete information. Furthermore, the prices of both produced goods are higher and the outputs are lower than their Walrasian levels. "

\footnotetext{
${ }^{11}$ Note that if a monetary contraction causes the change in the distribution of wealth, then prices of goods relative to the nonproduced good (money) will fall rather than rise. An implication of our result is that the decrease in supply associated with the increased uncertainty will cause prices in terms of money to fall less than they would under complete information.
} 
Proposition 2. ${ }^{12}$ Consider a Walrasian equilibrium with prices $\bar{P}_{x}$, $\bar{P}_{y}$ satisfying $\bar{P}_{x}>\bar{P}_{y}$ and employment levels $\bar{l}_{x}, \bar{l}_{y}$. The corresponding asymmetric information contract equilibrium $P_{x}, P_{y}, l_{x}, l_{y}$ satisfies $P_{x}>$ $\bar{P}_{x}, P_{y}>\bar{P}_{y}, l_{x}<\bar{l}_{x}$, and $l_{y}<\bar{l}_{y}$.

Proof: Comparing (3i) with (38) and (39) shows that it suffices to prove that $P_{x}>\bar{P}_{x}$ and $P_{y}>\bar{P}_{y}$. Suppose one of these inequalities failed. Define $P \equiv P_{x}^{\lambda_{1}} P_{y}^{\lambda_{2}}, \bar{P} \equiv \vec{P}_{x}^{\lambda_{1}} \vec{P}_{y}^{\lambda_{2}}$.

CASE $a: P_{x} \leqslant \bar{P}_{x}$. The market-clearing conditions (38) and (31) yield $l_{x}>\bar{l}_{x}$. Thus, the marginal productivity conditions (40) and (36) imply that

$$
\frac{P_{x}}{P} \geqslant \frac{\bar{P}_{x}}{\bar{P}}
$$

But since $P_{x} \leqslant \bar{P}_{x}$, (42) implies that $P_{y} \leqslant \bar{P}_{y}$. Market clearing requires that output of $Y$ be higher in the contract equilibrium, so $l_{y}>\bar{l}_{y}$. But the marginal conditions (37) and (41) then imply that

$$
\frac{P_{y}}{P}>\frac{\bar{P}_{y}}{\bar{P}}
$$

Now raise (42) to the power $\lambda_{1}$, (43) to the power $\lambda_{2}$, and multiply. This yields $P>\bar{P}$, which is inconsistent with $P_{x} \leqslant \bar{P}_{x}, P_{y} \leqslant \bar{P}_{y}$.

CASE $b: P_{y} \leqslant \bar{P}_{y}$. Market clearing implies that $l_{y} \geqslant \bar{l}_{y}$. Then (41) and (37) imply that $P_{y} / P \geqslant \bar{P}_{y} / \bar{P}$. This gives $P_{x} \leqslant \bar{P}_{x}$. The contradiction now follows exactly as in case $a$. Q.E.D.

Notice that although only one intermediate goods industry is unlucky in the sense of setting marginal product above marginal disutility, both are unlucky in suffering employment levels below the Walrasian level. Thus, there is something resembling a multiplier that, through general equilibrium effects, transforms the sub-Walrasian output and employment of one sector into a general "recession."

As in Section III, proposition 2 implies that, if we start in the steady state $P_{x}=P_{y},(1)$ a demand shock that creates price dispersion and keeps total Walrasian employment constant will reduce total employment under asymmetric information; (2) a shock that reduces Walrasian employment will reduce employment under asymmetric information by more; and (3) a shock that increases Walrasian employment will increase employment under asymmetric information by less.

We see that changes in the distribution of wealth will cause relative price movements, which create uncertainty on the part of laborers

\footnotetext{
${ }^{12}$ We must emphasize that proposition 2 depends importantly on the ordinal (i.e., Cobb-Douglas) preferences we have assumed (although we could have assumed any number of goods). The result generalizes to utility functions over $X, Y$, and $Z$ of the form $\phi(X, Y)^{\lambda} Z^{1-\lambda}$, where goods $X$ and $Y$ are gross complements.
} 
about their marginal value product. We have used the convention that unequal final goods prices are associated with uncertainty about the marginal value product of labor within each industry. To see that this is just a convention, note that in a world of perfect certainty free entry leads resources to be allocated across industries in such a way that prices are determined by minimum average costs. When firms have identical production functions, minimum average costs are the same. If we instead began with industries that had different cost functions, then the steady-state (no shock) situation would lead to final goods prices that are unequal. However, the profitability of labor would be equalized across industries. A shock that changed relative demands would, in the short run, cause the profitability of hiring labor to be unequal across industries. If workers knew only the distribution of profitabilities across industries and they thought their firm's labor profitability were a random drawing from that distribution, then a shock that changed demand from its steady-state value would cause uncertainty about labor productivity within each industry. By the arguments of this section, this would cause a drop in employment relative to the Walrasian level.

\section{Evidence and Conclusions}

A. Relative Price Variability as a Cause of Aggregate Output Variability

In Section IV we outlined a model in which relative price shocks make workers uncertain about their marginal value products. Firms have superior information about marginal products but are risk averse; when the profitability of employing labor in a given firm is low, it would like to reduce the wage bill. Because of the asymmetry of information, it cannot do this directly but must also reduce the employment level to persuade workers that their marginal products really are low.

Before discussing potential sources for the relative price shocks, we offer some evidence that is consistent with the implication that relative price shocks affect aggregate output. Note that proposition 2 implies that relative demand shocks which leave employment unchanged under full information will lower employment under asymmetric information. Thus, assuming that, on average, the actual relative demand shocks that impact on our economy would be neutral under symmetric information, our major empirical implication is that aggregate employment will fall, on average, in response to relative demand shocks.

Lilien (1982) has presented evidence that the level of unemploy- 
ment tends to be high when the cross-sectional variability of net employment is high. He found that the cross-sectional variability of employment can explain at least as much of the unemployment as can unanticipated decreases in the money supply. Unfortunately, Lilien does not examine the relationship between relative price shocks and the cross-sectional variability of net employment.

Fischer (1982) surveys the literature on relative price variability. He also studies the time-series behavior of aggregate output, relative price variability, and other macroeconomic variables. In a vector autoregression, relative price variability, when "put first," explains as much of the variability of output as interest rate, money, or inflation innovations (see his table 8), that is, about 10 percent of the total variability of output. When relative price variability is "put after" interest rates, money, and inflation, it does as well as inflation and money but worse than interest rates.

The comparatively high explanatory power of relative price variability for output is, of course, consistent with models other than ours. For example, all Fischer's results are consistent with a Walrasian model in which agents receive information that future output will fall but that components of output will fall in differing proportions. With a conventional money demand model this implies that prices will rise in the future in differing proportions, in turn raising present prices in differing proportions. Thus, the future decrease in output induces increases in expected inflation, variability of inflation, and nominal interest rates, which is exactly what Fischer finds. Fischer also suggests three other models that are consistent with his observations.

\section{B. The Causes of Relative Price Variability}

The model presented in Section IV assumes that a shift in the distribution of wealth creates a change in relative prices. There are clearly many sources of relative price variability other than changes in the distribution of wealth, for example, variability in technology, tastes, and the prices of imports and exports. We have focused on wealth redistributions to allow for comparisons with existing macroeconomic models.

In particular, assume that there is a wealth redistribution between nominal borrowers and lenders after an unanticipated movement in the price level. (Although our model has no money, it would not be difficult to append an additively separable utility of real balances to preferences. Furthermore, we could model borrowing and lending associated either with life-cycle effects or random shocks to income. ${ }^{13}$ )

\footnotetext{
${ }^{13}$ See Grossman and Weiss (1982) for an example of a mechanical transformation of an asymmetric information real economy to a nominal economy. An almost identical
} 
In such a model with nominal borrowing and lending, unanticipated inflation has important effects on the distribution of wealth.

In the United States, 50 percent of "wealth" is held in the form of nominal debt. ${ }^{14}$ If the economy is composed of two types of individuals, nominal borrowers and lenders, who share other wealth equally, then a 10 percent permanent drop in the price level increases the real wealth of lenders by 50 percent of 10 percent, or 5 percent. Borrowers' wealth falls by the same amount. To the extent that the permanent drop of 10 percent in the price level is associated with expected deflation, there will be a second effect in the wealth distribution in the same direction. Namely, the real price of long-term nominal debt will rise due to the decrease in the nominal interest rate. People over 55 (the "old") tend to be nominal creditors while people under 55 (the "young") tend to be nominal debtors. Fischer and Modigliani (1978) estimate (to within an order of magnitude) that a 1 percent unanticipated increase in the price level will transfer wealth with a flow value of about 1 percent of GNP.

Wealth redistributions have no effect on relative prices if wealth is redistributed between groups that have the same homothetic preferences. However, there is some evidence that there are systematic differences by age among individuals in their preferences. Michael (1979, p. 41) used the Bureau of Labor Statistics' consumer expenditure survey to find that there are systematic and significant differences among individuals' consumption proportions by age. The classification of borrowers and lenders by age may not be the most useful for tracing the consequences of the wealth redistribution. We mention it here because it is the only classification for which there is evidence that individuals are jointly sorted by desired consumption proportions and debt positions.

There are some other obvious sources of wealth redistributions that may be of sufficient magnitude to have caused observed output fluctuations. For example, unanticipated changes in nominal interest rates due either to real or to nominal factors redistribute wealth between long-term borrowers and lenders, and this could be a source of relative price variability. Alternatively, large decreases in the real value of assets such as houses and stocks can cause substantial redis-

transformation could be made here. An essential difference is that our model of Sec. IV will not work with complete endowment insurance. If the two different types of traders have perfectly insured each other, then the particular realization of the endowment distribution will not affect the relative wealth position. Similarly, unanticipated price movements will have no real effects if all contracts are indexed.

"See Friedman (1982). By "wealth" we mean the value of total assets held by those who save. Thus, while inside debt is not usually considered net wealth, it is net wealth to the consumers who are saving. If those people who pay the taxes to finance government debt interest payments are the same as the holders of government debt, then the wealth redistribution will only be associated with inside debt. 
tributions of wealth between the young and the old. Finally, exogenous changes in the productivity of capital could be the cause of a change in the real value of assets.

\section{Relative versus Aggregate Demand Shifts}

The previous discussion may obscure some of the difference between our model and aggregate demand models of the business cycle. To the extent that changes in aggregate demand cause wealth redistributions that induce employment fluctuations, there is some similarity between our model and aggregate demand models. One important difference, however, is that there is no reason in our model why the sign of the aggregate demand shock should matter. A large unanticipated inflation can cause the same relative price shift as a large unanticipated deflation. ${ }^{15}$ Hence there is no presumption that unanticipated inflation is expansionary whereas unanticipated deflation is contractionary. To a first approximation (i.e., where the Walrasian equilibrium total output is independent of the wealth distribution), the absolute value of the unanticipated price level change should be negatively correlated with output in our model. Furthermore, if relative price variability is an independent variable explaining output, then unanticipated inflation should have little incremental explanatory power.

Blejer and Leiderman (1980) and Fischer (1982) use innovations in inflation and relative price variability as explanatory variables for output. Their results suggest that each variable has some independent explanatory power for output in the post-World War II United States. Fischer (1982, fig. 3) and Sims (1980, table 3) both find that in the post-World War II period positive price innovations precede a decrease in output. We conclude from this evidence that, in the postWorld War II period, although the data suggest an independent effect of price innovations, the signs are the reverse of those predicted by the models of Sargent, Lucas, or Barro (see Barro [1981] for a survey of models in which unanticipated inflation causes an increase in output).

The period before World War II is likely to be favorable to the unanticipated inflation model. Sims (1980, table 3) finds that negative price innovations precede decreases in output in the period between World War I and World War II. Unfortunately, we have not been

\footnotetext{
${ }^{15}$ Of course in a Walrasian model it is possible that a wealth redistribution from group A to group B will cause an expansion of output while the reverse redistribution will cause a contraction. However, we prefer to maintain the presumption that the wealth redistribution has no effect on the Walrasian equilibrium.
} 
able to find any evidence that distinguishes the relative price variability hypothesis from the unanticipated inflation hypothesis in that period. In the pre-World War II period, large unanticipated deflation may well be a proxy for high variability of relative prices. This is consistent with the data of tables 2 and 6 in Parks (1978).

Thus it seems that further empirical research is needed to distinguish the hypothesis that unanticipated falls in money (or prices) decrease output from the hypothesis that monetary or price level shocks of any sign decrease output. In addition, further theoretical research is required to develop models in which the sign of the publicly observed shock, as well as its size, affects output. One such contribution is that of Holmstrom and Weiss (1982), who suggest that when individuals confuse idiosyncratic and aggregate shocks, as in Lucas (1972), the direction of aggregate shocks matters.

\section{References}

$\rightarrow$ Azariadis, Costas. "Employment with Asymmetric Information." Q.J.E. 98 (suppl.; 1983): 157-72.

Barro, Robert J. "The Equilibrium Approach to Business Cycles." In Money, Expectations, and Business Cycles: Essays in Macroeconomics. New York: Academic Press, 1981.

$\rightarrow$ Blanchard, Olivier J. "Wage Indexing Rules and the Behavior of the Economy." J.P.E. 87 (August 1979): 798-815.

$\rightarrow$ Blejer, Mario I., and Leiderman, Leonardo. "On the Real Effects of Inflation and Relative-Price Variability: Some Empirical Evidence." Rev. Econ. and Statis. 62 (November 1980): 539-44.

$\rightarrow$ Dasgupta, Partha S.; Hammond, Peter J.; and Maskin, Eric S. "The Implementation of Social Choice Rules: Some General Results on Incentive Compatibility." Rev. Econ. Studies 46 (April 1979): 185-216.

Fischer, Stanley. "Relative Price Variability and Inflation in the United States and Germany." European Econ. Rev. 18 (May/June 1982): 171-96.

Fischer, Stanley, and Modigliani, Franco. "Towards an Understanding of the Real Effects and Costs of Inflation." Weltwirtschaftliches Archiv 114, no. 4 (1978): 810-33.

Friedman, Benjamin M. "The Changing Role of Debt and Equity in the United States.” Manuscript. Cambridge, Mass.: Harvard Univ., 1982.

$\rightarrow$ Grossman, Sanford J., and Hart, Oliver D. "Implicit Contracts, Moral Hazard, and Unemployment." A.E.R. Papers and Proc. 71 (May 1981): 3017 .

$\longrightarrow$ "Implicit-Contracts under Asymmetric Information." Q.J.E. 98 (suppl.; 1983): 123-56.

$\rightarrow$ Grossman, Sanford J., and Weiss, Laurence. "Heterogeneous Information and the Theory of the Business Cycle." J.P.E. 90 (August 1982): 699-727.

$\rightarrow$ Harris, Milton, and Townsend, Robert M. "Resource Allocation under Asynmetric Information.” Econometrica 49 (January 1981): 33-64.

$\rightarrow$ Hart, Oliver D. "Optimal Labour Contracts under Asymmetric Information: An Introduction.” Rev. Econ. Studies 50 (January 1983): 3-35. 
Holmstrom, Bengt, and Weiss, Laurence. "Managerial Incentives, Investment, and Aggregate Implications. Part I. Scale Effects." Mimeographed. Evanston, Ill.: Northwestern Univ., 1982.

$\rightarrow$ Lilien, David M. "Sectoral Shifts and Cyclic Unemployment." J.P.E. 90 (August 1982): 777-93.

$\rightarrow$ Lucas, Robert E., Jr. "Expectations and the Neutrality of Money." J. Econ. Theory 4 (April 1972): 103-24.

$\rightarrow$ Michael, Robert T. "Variation across Households in the Rate of Inflation." $J$. Money, Credit and Banking 11 (February 1979): 32-46.

$\rightarrow$ Myerson, Roger B. "Incentive Compatibility and the Bargaining Problem." Econometrica 47 (January 1979): 61-73.

$\rightarrow$ Parks, Richard W. "Inflation and Relative Price Variability." J.P.E. 86 (February 1978): 79-95.

$\rightarrow$ Sims, Christopher A. "Comparison of Interwar and Postwar Business Cycles: Monetarism Reconsidered." A.E.R. Papers and Proc. 70 (May 1980): 25057.

Taylor, John B. "Aggregate Dynamics and Staggered Contracts." J.P.E. 88 (February 1980): 1-23. 